\title{
DIGITAL QUALITY MANAGEMENT IN CONSTRUCTION INDUSTRY WITHIN BIM PROJECTS
}

\author{
Martin Stransky, Petr Matejka \\ Czech Technical University in Prague, Czech Republic \\ martin.stransky@fsv.cvut.cz,petr.matejka@fsv.cvut.cz
}

\begin{abstract}
The paper is focused on digital processes related to quality management within Building Information Modelling (BIM) projects. Even though BIM is among its other advantages considered helpful in the design phase to support quality management by clash detection, there has been only little improvement of quality management in the execution phase related to BIM projects, as well as limited research in this field. Despite the fact that some construction companies already use certain applications to process quality management digitally, it can be said that current practice of quality management in the construction industry is generally dependent on hand-written documents with photos and other digital media, which are in no way related to the hand-written documents. This is especially a common practice in rural areas. Therefore, these hand-written documents have to be later associated with corresponding photos and other digital media in order to make a fully transparent report for involved project stakeholders. This process requires a lot of manual and repetitive work for all involved project stakeholders, thus resulting in high error rate. With increasing number of defects, it is almost impossible to manage all defects appropriately and evaluate their statuses. That is why a new digital quality management system shall be proposed to make the process of quality management transparent and effortless for all involved project stakeholders. A digital quality management system can be associated with BIM projects, but does not necessarily has to, it can work with 2D project documentation as well as with 3D BIM models. The paper describes current practice of quality management in construction industry and outlines new possibilities of digital quality management systems in connection with BIM projects.
\end{abstract}

Keywords: BIM, quality management, digitalization, construction.

\section{Introduction}

Project's quality management can be defined by national, international standards (e.g. ISO 9000, ISO 9001) or industrial standards and client's requirements [1]. The aim of quality management in the construction industry is to ensure the quality of construction works according to defined standards and client's requirements. Therefore, it is of high interest to contractors to satisfy those standards and requirements, if they want to maintain their position on the demanding and competitive construction market [1]. Despite the fact, that quality assurance is a key element for successful execution of a construction project, there has been only limited improvement in quality management with increasing digitalization of construction industry [2]. Even though it is usual that managing workers at the construction site have a smart phone or a tablet at their disposal, therefore it would be expected that they use an application to check the quality of the project, it is still not common that even leading investors or general contractors use an application for this purpose on most of their projects. There are several reasons why these applications are still not widely used on construction projects. These reasons will be stated and analysed in this article based on a questionnaire, which serves as a basis for this article.

\section{Literature review and current situation of quality management}

Many construction companies are certified with ISO 9001 [3], which is based on seven quality management principles. These principles are the foundation stone of quality management to certified construction companies. These seven principles are:

- customer focus;

- leadership;

- engagement of people;

- process approach;

- improvement;

- evidence-based decision making;

- relationship management [4]. 
This article presumes that the current practice of quality management in construction industry does not comply with these principles in their full potential. Statements why it is assumed that quality management in construction industry does not comply with these principles are provided below.

Customer focus principle regarding the quality management is currently not satisfied, because clients are not involved in the process of quality management. It can be said that general contractors have their own database of quality inspections in Excel spreadsheet, which is in no way accessible to clients. Clients do have the possibility to report a quality defect, but do not have the possibility to check their status of reparation.

Leadership principle in innovation is not satisfied to its full potential, since major construction companies do not use the latest technologies for their processes. Hence, digitalization of quality management processes shall occur.

Principle of engagement of people in the quality management is poorly satisfied [5], because only a responsible worker for quality management has an overview of all recorded quality inspections and defects. Therefore, other project stakeholders have no information of recorded quality inspections and defects. That is why one quality defect might be reported several times by several workers. That is why a digital application, which is accessible to all project stakeholders, is required.

Currently process approach principle is satisfied in a limited way, because quality inspections and defects are reported to the responsible worker, however, monitoring of individual quality inspections and defects is complicated and requires redundant work of involved project stakeholders. Reporting worker has to carry out quality inspection and report a defect into his independent database and later report it to the responsible worker. The responsible worker has to check and evaluate this reported defect and possibly repair it, if necessary. Then he has to inform the reporting worker that the defect has been repaired or rejected, so he can change the status of the quality defect in his database.

As far as improvement principle in this article is understood as digitalization of the quality management process, it can be said that it is not yet satisfied in most construction projects.

Evidence-based decision making principle is an essential feature throughout all project's phases. In order to make a deliberate decision it is important to have a set of data, which can serve as a basis for decision making [2]. This statement is also valid for quality management. Therefore, a structured database of former quality inspections and defects shall be created. That is why all quality inspections and defects shall be recorded during the execution phase into a unified and structured database [6], which can be then used in the warranty phase. This will give the warranty engineer strategic information about the quality defects, which occurred during the execution phase. In this way he will have an overview, if the claimed defect occurred due to quality defect during the execution phase or if it is a completely new defect. It is also a strategic tool for clients, who search for contractors or subcontractors for their projects, because they have a database of their work quality. Based on this information the client can decide whether to do business with the cheapest contractor, who possibly caused the biggest losses due to poor quality on past projects.

In order to manage relationships principle with involved project stakeholders, it is important to be fair, transparent and responsible. That is why quality management shall be executed in this manner. It means reporting quality defects in a standardised way, so everybody understands what is asked from him as well as evaluating the status of defect in a transparent way, so everybody can take responsibility for their defects. In order to achieve this, it is vital to have an application, which is accessible to all involved project stakeholders and generates standardised reports with enough transparent information that describes the quality defect comprehensibly.

\section{Used methods}

This article adopted a questionnaire, which was filled in by construction project stakeholders. The aim of the questionnaire was to analyse the current practice of quality management in the construction industry. Deciding questions of the questionnaire were whether construction companies carry out quality inspections and if they use a quality management application. The respondent was directed to different questions based on his answers to deciding questions. If the respondent's company does not carry out quality inspections, then the respondents were directed to the end of the questionnaire, if the respondent's company does carry out quality inspections, then the respondents were directed to the 
remaining questions. The questionnaire consisted of relevant questions for those respondents, whose companies use a quality management application and for those, whose do not use a quality management application.

\section{Questions of the questionnaire were the following:}

- Does your company carry out quality inspections?

- Which project stakeholder do you work for?

- Does your company have a predefined inspection and test plan?

- Who carries out quality inspections in your company?

- Does your company use a quality management application?

\subsection{Section of questions, if a company does not use a quality management application.}

- Do you create a list of quality inspections (for example, in Excel spreadsheet)?

- Is it necessary to create a report after carrying out a quality inspection?

- Which attachments are required for quality inspections?

- Does your company submit a report from quality inspections to responsible project stakeholders?

- Does your company evaluate statuses of quality inspections?

- Do you consider your process of quality management transparent?

- Would you like to change your current process of quality management?

\subsection{Section of questions, if a company uses a quality management application.}

- Does this application work with project documentation?

- Is it possible to work with BIM models in the application?

- Which attachments do relate to quality management?

- Is it possible to insert all required attachments into the application?

- Are those attachments directly related to the quality inspection?

- Is it possible to generate a report of quality inspection?

- Are the generated reports user definable?

- Is it possible to evaluate statuses of quality inspections?

- Is this application accessible to other project stakeholders?

- Do you consider use of this application transparent?

- Do you consider use of this application beneficial?

\section{Research questions}

1. What is the current practice of quality management in the construction industry?

2. What are advantages and disadvantages of current quality management practice?

3. Why is the current practice the major process of quality management nowadays?

4. What attachments are required for quality management?

5. What are the possibilities of quality management digitalization?

6. Who should use and have access to a digital application for quality management?

7. How can a digital application be linked to current practice of quality management?

8. Why is it important to have the possibility to define a different report template for each project?

9. Why is it important that the digital application works with project documentation?

10. Why is it important to have a manager of project documentation on every construction project?

11. Why is it important that the digital application works in offline mode?

12. What are the limitations of implementation of quality management application?

13. How to implement digital application into a construction project?

14. Quality management within BIM projects? 


\section{Results}

The questionnaire was completed by 103 project stakeholders from the construction industry. From 103 respondents $66 \%$ of respondents work for general contractors, $29 \%$ work for investors, $1 \%$ work for subcontractors and $4 \%$ work for different project stakeholders. Based on the number of respondents and their various occupations, it can be said that the questionnaire qualitatively represents the current situation of quality management in the construction industry.

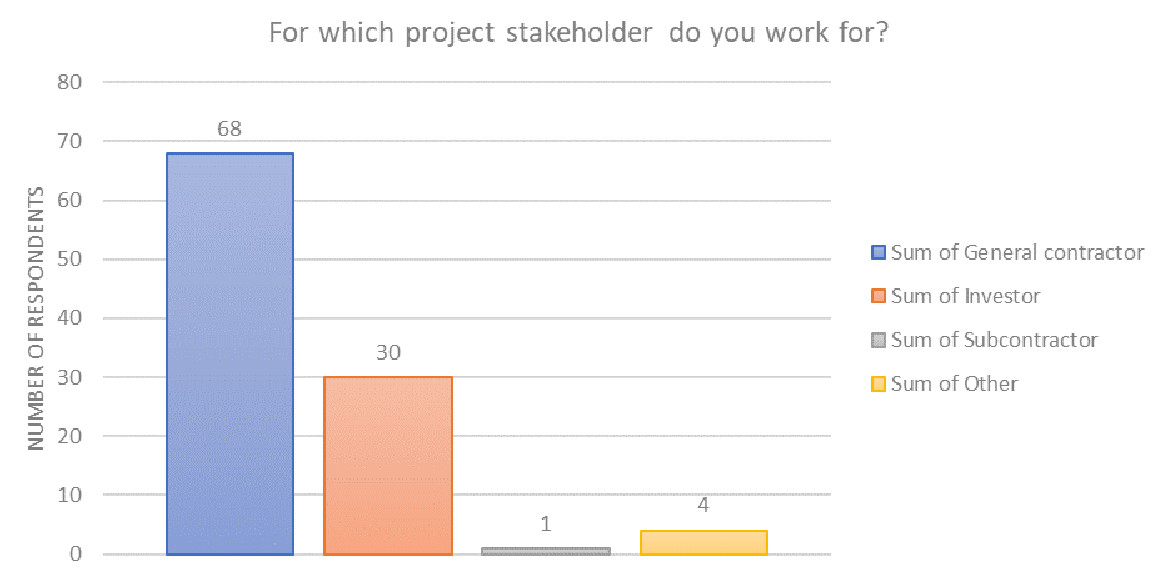

Fig. 1. Representation of respondents and their various occupations

Out of 103 respondents $98 \%$ of respondents stated that their company carries out quality inspections, only $1 \%$ of respondents stated that they do not know if their company carries out quality inspections and the remaining $1 \%$ of respondents stated another answer. This answer was that they carry out quality inspections only if they work with subcontractors, otherwise they monitor quality of their work internally. Based on the provided results it can be interpreted that carrying out a quality inspection is a common practice in the construction industry, because $98 \%$ of companies do carry out a quality inspection.

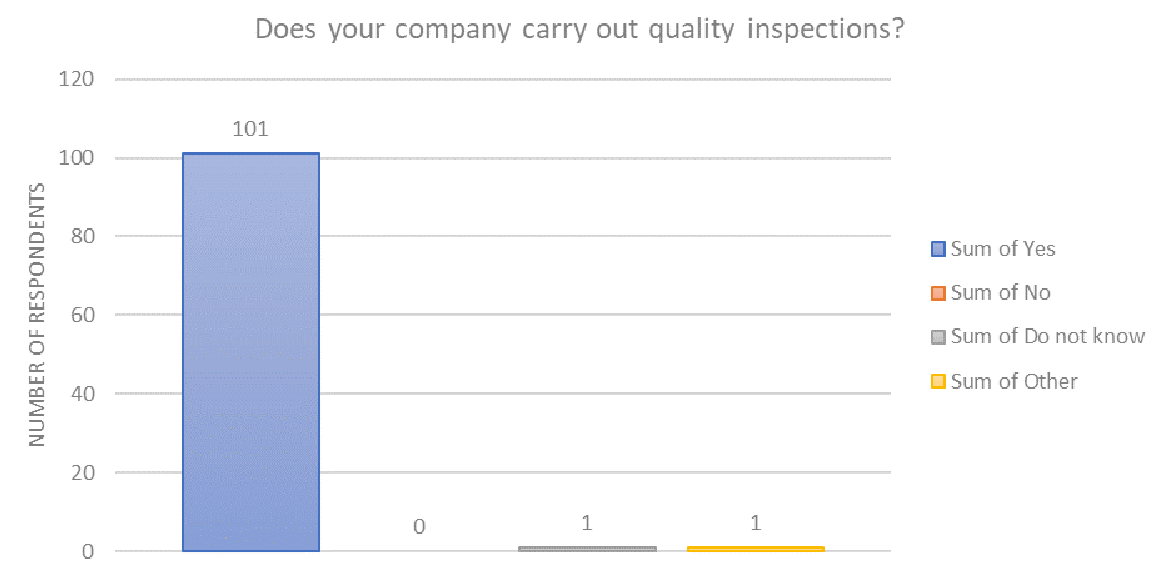

Fig. 2. Figure presenting if companies carry out quality inspections

The questionnaire also involved a question, if companies have a predefined inspection and test plan. Out of 103 respondents $88 \%$ of respondents stated that their company has a predefined inspection and test plan, only $6 \%$ of respondents have no predefined inspection and test plan and $6 \%$ of respondents do not know if their company has a predefined inspection and test plan. Therefore, it can be presented that most construction companies do have a predefined inspection and test plan and it is known to their employees. 


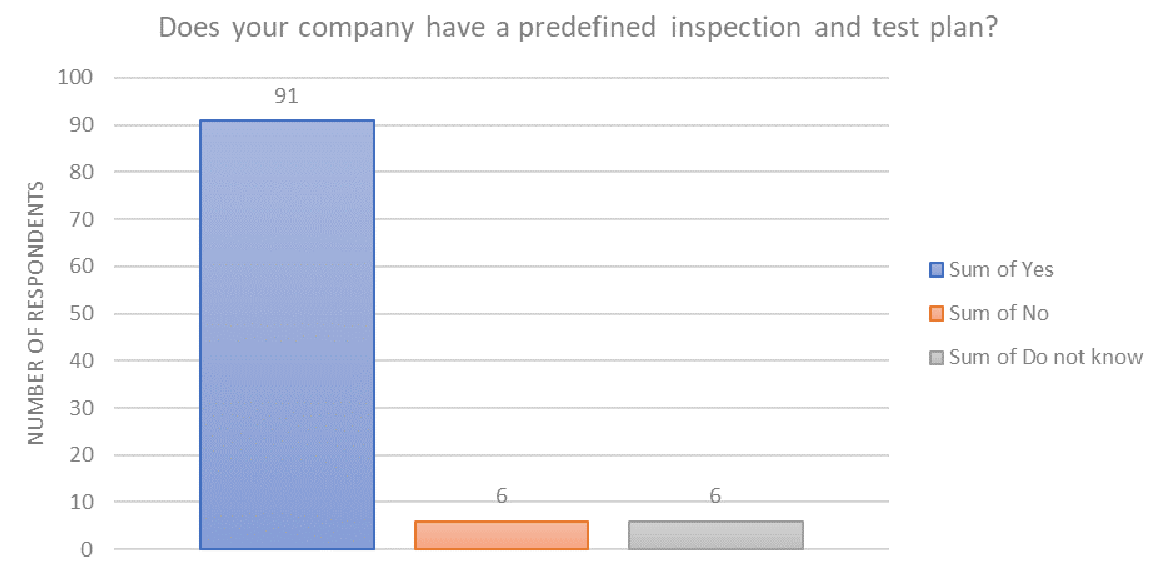

Fig. 3. Figure presenting if companies have predefined inspection and test plan

\section{What is the current practice of quality management in the construction industry?}

The questionnaire indicates that $98 \%$ of project stakeholders within the construction industry carry out quality inspections and $88 \%$ respondents have predefined inspection and test plan, which is carried out by internal and external project stakeholders. It also indicates that $44 \%$ of project stakeholders do not use an application for quality management; only $21 \%$ use an application for quality management. Remaining $35 \%$ of respondents do not know if their company uses an application for quality management. This statistic indicates that it is common practice not to use an application for quality management. If we assume that half of respondents answered that they do not know about the use of a quality management application in their company, then $61,5 \%$ of respondents do not use an application for quality management. Hence, it can be said that current practice of quality management in the construction industry is that an application for quality management is not used.

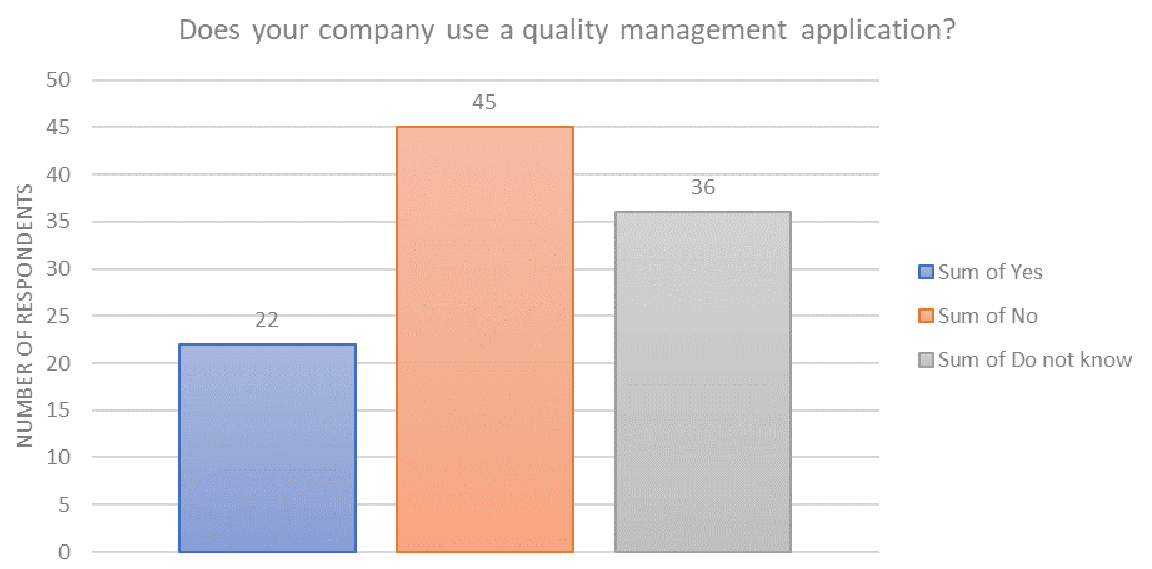

Fig. 4. Figure presenting if companies use quality management application

Out of $44 \%$ respondents, who do not use an application, $80 \%$ rely on an Excel spreadsheet, where they manage quality inspections. $69 \%$ of respondents, who do not use a digital application, indicated that they have to manually create a report from the inspection with attachments (e.g. photo, video, text, sketch, drawing).

Also $71 \%$ of respondents, who do not use an application, indicated that they submit manually created reports to responsible project stakeholders. $68 \%$ of respondents, who do not use an application, indicated that they evaluate statuses of quality inspections in an Excel spreadsheet.

Despite manual work related to quality management without use of an application, $67 \%$ of respondents, who do not use an application, indicated that they consider their current process as transparent and only $27 \%$ would like to change and possibly digitalize their processes. 


\section{Do you create a list of quality} inspections (for example in Excel spreadsheet)?

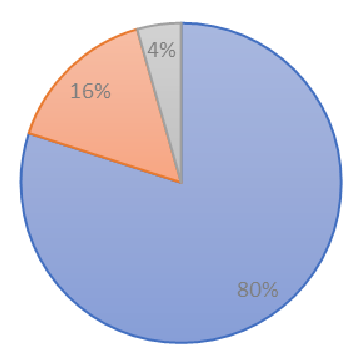

Is it necessary to create a report after carrying out a quality inspection?

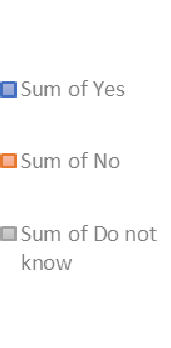

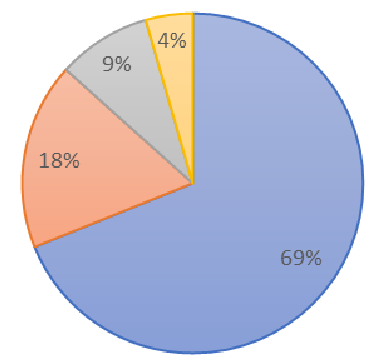

Fig. 5. and 6. Figures presenting if quality inspections are recorded in list and if it is necessary to create report after carrying out quality inspection

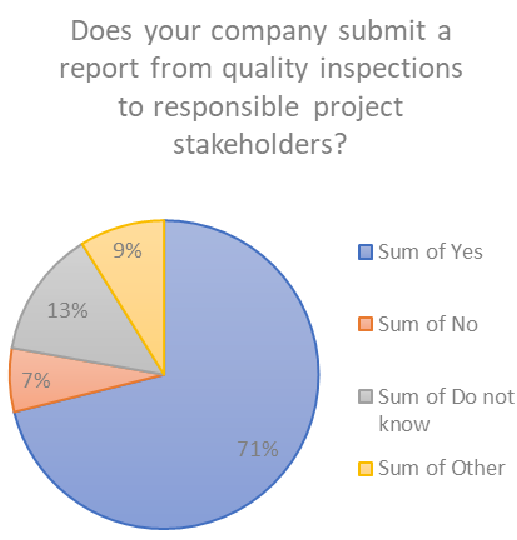

Does your company evaluate statuses of quality inspections?

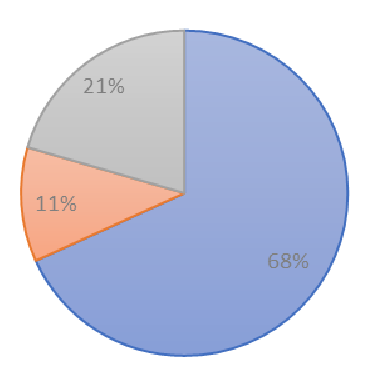

Sum of Status is

monitored

$\square$ Sum of Status is

not monitored

$\square$ Sum of Do not

know

Fig. 7. and 8. Figures presenting if company submits reports from quality inspections and if company evaluates statuses of quality inspections
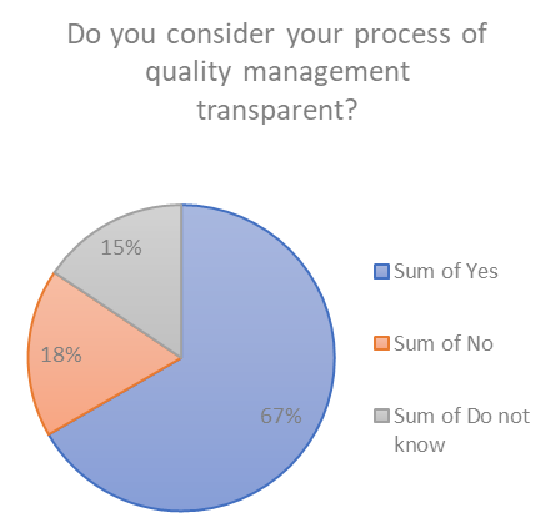
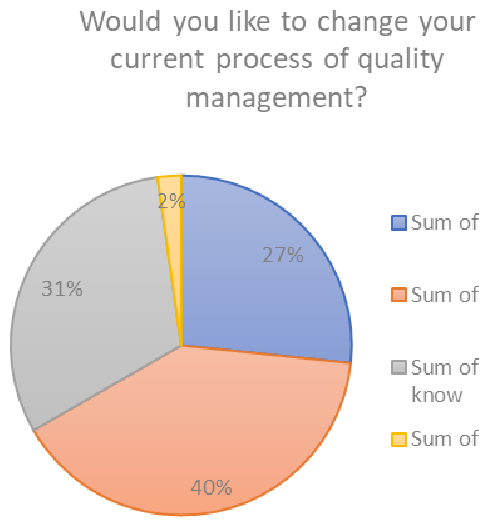

口Sum of Yes

$\square$ Sum of No

$\square$ Sum of Do not

know

$\square$ Sum of Other

Fig. 9. and 10. Figures presenting if respondents consider their process of quality management transparent and if they would like to change their process of quality management

2. What are advantages and disadvantages of current quality management practice?

Advantages of the current practice are the following:

- current process is known to most project stakeholders, thus requires no additional implementation and support of specialists, 
- current construction contracts are adapted to hand-written and signed reports, that is why the current manual process of creating reports is regarded as valid,

- it does not impose additional cost for application licences to the project.

Disadvantages of the current practice are as follows:

- it requires redundant work for involved project stakeholders,

- it is very complicated to evaluate statuses of recorded quality inspections, especially with high number of reported quality inspections,

- it is necessary to manually link quality inspections with corresponding attachments in order to create a transparent report for responsible project stakeholders.

\section{Why is the current practice the major process of quality management nowadays?}

As it was already mentioned in the second research question, the current contractual framework is adapted to hand-written and signed documents, which are regarded as valid. As well as it is well known to all project stakeholders and imposes no direct additional cost to the project. That is why the current practice is still widely used.

\section{What attachments are required for quality management?}

Respondents, who do not use an application, indicated that the following attachments are required to carry out a quality inspection:

- photography (89\%), video (18\%), audio (4\%), text (89\%), sketches (47\%) and other (2\%). Other answers consisted of drawings and technical data sheets.

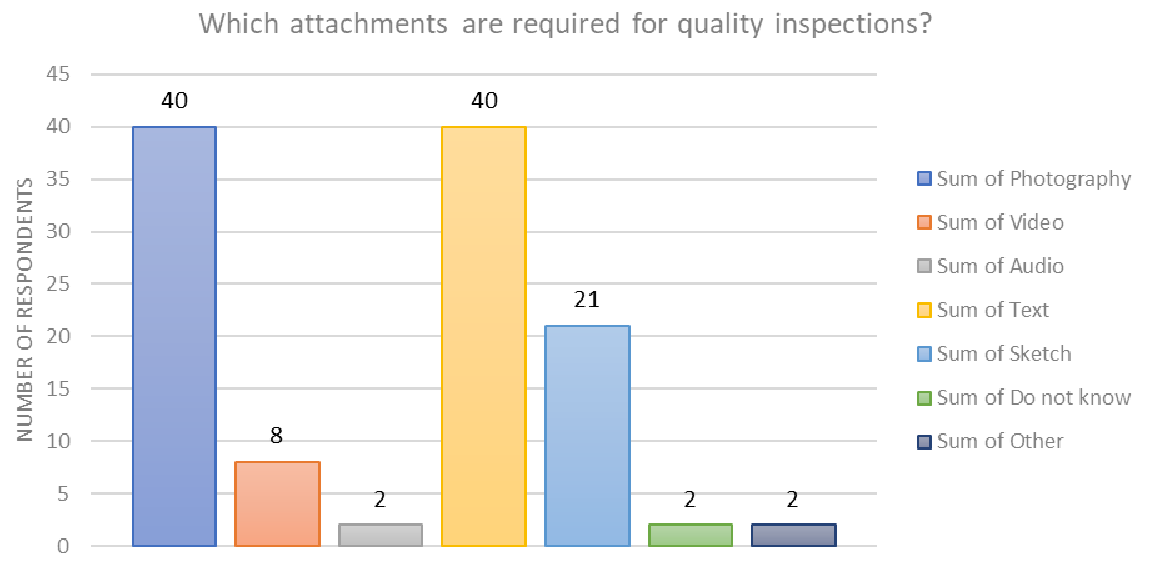

Fig. 11. Figure displaying which attachments are required to carry out and document quality inspection if no application is used

Respondents, who use an application, indicated that the following attachments are required to carry out a quality inspection:

- photography (100\%), video (64\%), audio (32\%), text (91\%) and sketches (82\%) and other $(5 \%)$. Other answers consisted of drawings with authors' notes.

Based on the answers it can be said that an application allows its users to attach bigger variety of attachments, because respondents, who do not use an application, use in most cases only photography and text to enhance the transparency of a quality inspection. Whereas respondents, who use an application, use in most cases photography, video, text and sketches to enhance the transparency of a quality inspection. This without a doubt contributes to better understanding of the reported quality inspections to responsible project stakeholders. 


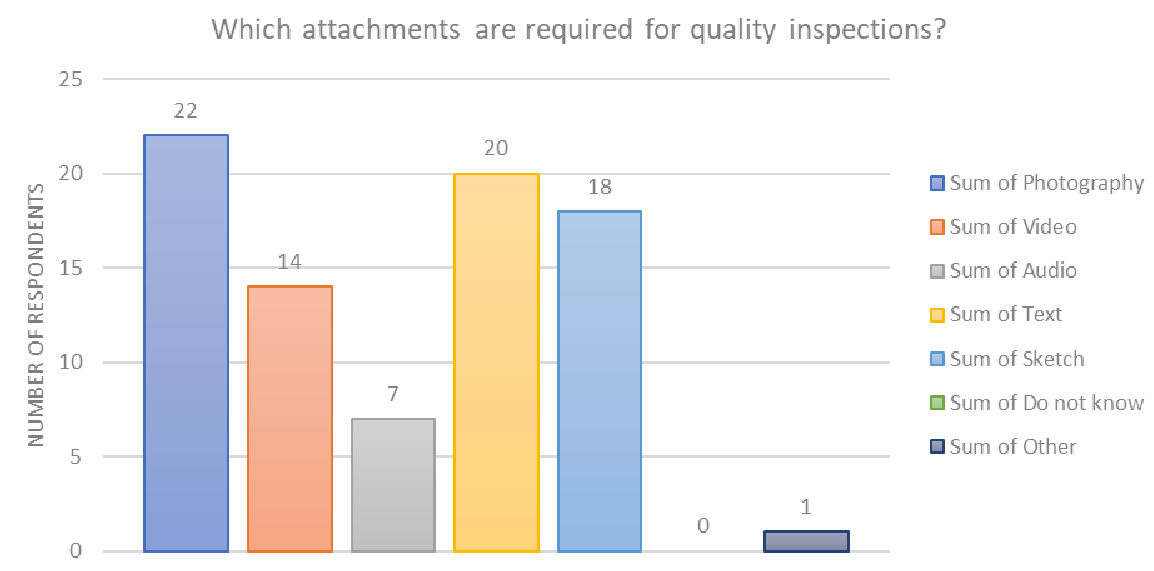

Fig. 12. Figure displaying which attachments are required to carry out and document quality inspection if application is used

\section{What are the possibilities of quality management digitalization?}

Possibilities of quality management digitalization are the following:

- standardization of processes and documents - since work with an application is unified, it will standardize processes related to quality management,

- improvement of transparency - since all involved project stakeholders can have permission to an application, it will enhance transparency, as well as all required attachments are related directly to the corresponding quality inspection, it is easy to find all relevant attachments in the future,

- added value - project stakeholders, who use an application, have actual project documentation at their disposal on the construction site in any given moment as well as use of modern technology leaves a good impression on clients,

- higher engagement of people - since any project stakeholder can be granted permission to an application, it offers the possibility to cooperate digitally via common platform,

- customer focus - because the client can be involved into the process of evaluating quality inspections via an application, he can monitor the statuses of remediation,

- leadership in use of technology - project stakeholders, who use an application for quality management, present themselves as leaders in use of technologies,

- improved evidence-based decision making - records of quality inspections can be later evaluated and assessed for future projects, it also serves as a decision-making tool for clients who are tendering contractors and subcontractors, because statistics of contractor's and subcontractor's quality of work can be obtained based on the data from past projects,

- improved relationship with project stakeholders - as far as more attachments are related directly to quality inspections, it makes it more effortless for responsible project stakeholders to understand the reported defect as well as evaluation of statuses is transparent, so everyone can see if a defect for which he is responsible had been approved or not.

\section{Who should use and have access to a digital application for quality management?}

Respondents indicated that $82 \%$ site engineers, $66 \%$ assistant site engineers, $53 \%$ quality engineers and $68 \%$ investor's supervisors carry out quality inspections. Therefore, technicians with these roles should have access to a quality management application. One answer even stated that all technicians and workers shall carry out quality inspections. Based on the provided answers it can be said that general contractor's and investor's technicians shall have access to a quality management application. The authors of this article recommend that subcontractors do have a passive access to an application in order to have the possibility to cooperate with other project stakeholders via common digital platform. 


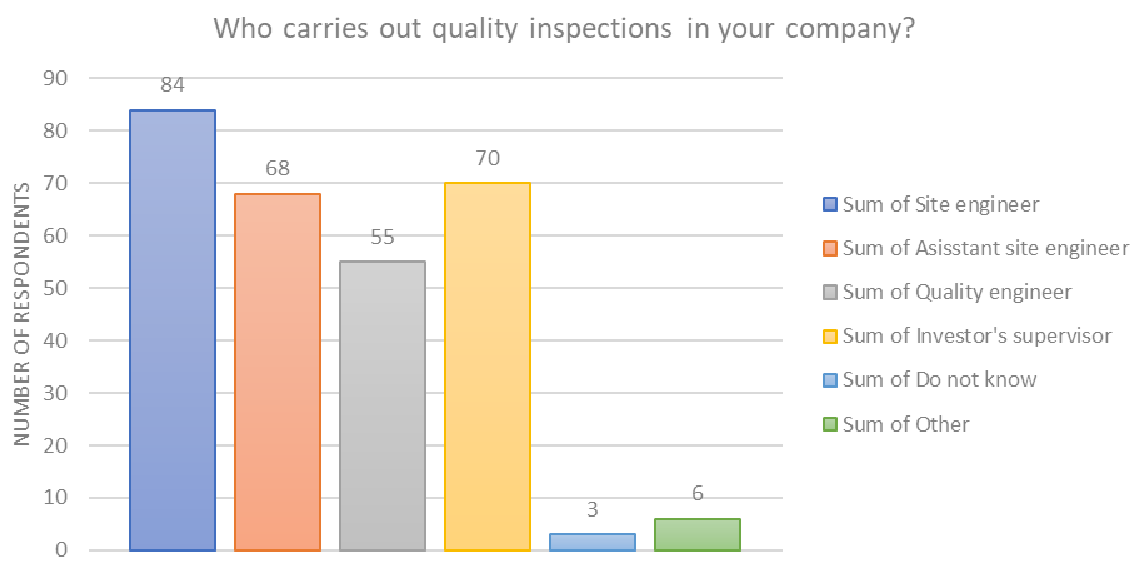

Fig. 13. Figure representing who carries out quality inspections in companies of respondents

Three respondents stated that they do not know who carries out quality inspection in their company. Six respondents stated other answers, such as the project manager, quantity surveyor, department of quality management and other technicians.

\section{What measures shall be taken in order to link a digital application to current practice of quality management?}

As mentioned in the third research question, the current practice is a major process of quality management due to contractual framework. That is why use of a quality management application shall be first adapted into contractual agreements, so both contractual parties regard the use of a quality management application and generated reports or digital approvals of quality inspections via common platform as valid.

\section{Why is it important to have the possibility to define a different report template for each project?}

It is important to have the possibility to define a different report template for each project due to the fact that both contractual parties have to agree on one unified report, which can change from one project to the other. It can occur that an application is paid by the general contractor, who has his own standardized report template, however, the client can insist on his standardized report template, which shall be implement into an application.

\section{Why is it important that a quality management application works with project documentation?}

An application which works with a project documentation provides its users with an overview of all quality inspections situated on a particular drawing, which helps its users easily display all quality inspections situated on one particular drawing (e.g. users can display all quality inspections situated on the floor plan of third level).

When generating a quality inspection report from an application, a viewport of the corresponding drawing can be added into the report to enhance an insight for the responsible project stakeholder. Despite the fact that author of the questionnaire did not add drawings as a predefined answer of the required attachments for quality inspection, two respondents answered that drawings are required attachments while creating a quality inspection report.

All project stakeholders, who have permission to an application, have always complete actual project documentation at hand while working on a construction site, as far as they carry a smart phone or a table with them. It saves them a lot of time by not having to walk back to their office and searching for the required drawing, while handling with an issue at the construction site. 


\section{Why is it important to have a manager of project documentation on every construction project?}

It is important to have a manager of project documentation on every construction project, since actual project documentation shall be uploaded to an application database, so everyone works with the same actual drawings. Another reason is that project documentation is usually stored in other applications as well, which requires thorough management.

\section{Why is it important that a quality management application works in offline mode?}

As it was already mentioned in the tenth research question, it is of great help to project stakeholders, if they have complete and actual project documentation at their disposal at any given moment. Since construction sites are not always located in urbanized areas with the mobile Internet connection or with Wi-Fi connection, it is important to provide all content offline. Internet connection is especially an issue in the rural areas. In this way anyone can work offline and later synchronize the created content onto a common server once the Internet connection is available.

\section{What are the limitations of implementation of quality management application?}

If we do not take into consideration construction projects of international importance, where English or another worldwide language is used as the working language, it can be generally said that most construction site technicians and workers speak only their mother language. Hence, it is vital that an application is available in the local language. It can be a problem for application developers.

According to the Labor Force Statistics from the Current Population Survey, which was carried out by the United States Department of Labor in 2018, the average age of construction and building inspectors is 51 years and the average age of construction managers is 46,3 years [7]. According to the U.S. Census Bureau statistics, the median age of all people living in rural areas is 43 years, compared with 36 years for urban areas [8]. Hence, the aging labour force is especially a limitation in rural areas. Therefore, it can interpreted that potential users of a quality management application are older and experienced people, who are used to current processes and are not likely to change their workflow easily. They are a generation of people, who did not grow up surrounded by IT technologies, hence, do not easily accept digitalization of current processes.

As far as most applications are developed and administrated in one country, it is complicated for its users to search for assistance when needed in their native language. That is a disadvantage of small construction companies, which cannot effort to have internal application support to assist its users and help them with the setup of a project. However, even many major construction companies are not willing to pay internal application support and, if they do, it is a challenge to build up a clear network, so all users know whom to contact when needed. That is why application users do not have enough assistance, when they need it.

\section{How to implement digital application into a construction project?}

Despite the fact that this topic would require a thorough research on its own, a general answer in this article is provided. To support implementation of any digital application it is important to provide the following:

- fully translated application into the local language,

- not a robust solution, which everyone can easily understand and work with, because construction technicians and workers are not IT specialists and are generally older people,

- accessible licencing policy, so all project stakeholders can effort to pay a licence,

- application support provided in the local language,

- digital leader in a company, who will support other colleagues,

- committed team to adopt new solutions.

\section{Quality management within BIM projects?}

The questionnaire indicated that $45 \%$ of quality management applications can work with BIM models. That means that only 10 respondents out of 103 respondents $(10 \%)$ can manage quality inspections in connection with BIM models. Therefore, there is a lack in implementation of digital 
applications for quality management in connection with BIM models within the construction industry. A further research is hence required to propose a solution how to implement digital applications for quality management into the construction industry and to propose possible procedures related with quality management within BIM projects.

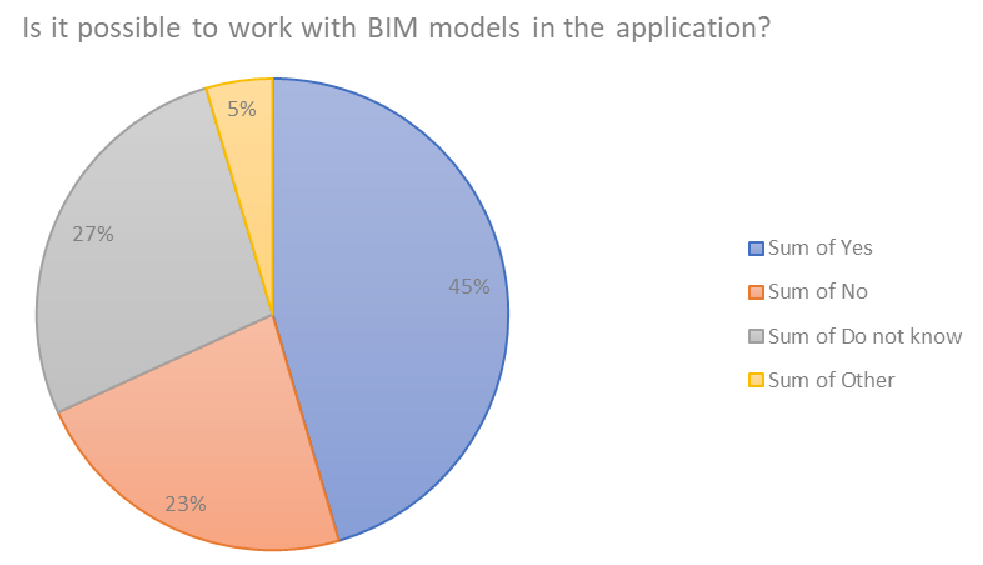

Fig. 14. Figure displaying if BIM models can be managed in quality management applications

\section{Conclusions}

1. The questionnaire proved that the current practice of quality management in the construction industry does not comply with seven principles of ISO 9001 in their full potential.

2. It was discovered that the current practice of quality management relies on lists of quality inspections, which are not connected with required attachments and must be therefore subsequently manually connected to a quality report. Thus, requiring a lot of manual work and not supporting the process approach principle.

3. $71 \%$ of respondents, who do not use an application, answered that they submit a quality inspection report to other project stakeholders and $69 \%$ of respondents, who do not use an application, answered that they evaluate statuses of quality inspections. These results might indicate that the current practice of quality management does support the principles of engagement of people, customer focus and relationship management. However, if we take into consideration that only the owner of the list has an overview of quality inspection statuses, it can be said that this procedure does not involve other project stakeholders to take active role in the evaluation of quality inspections and thus does not completely fulfil the potential of the mentioned principles.

4. It was discovered that, despite the manual work connected with the current practice of quality management, only $27 \%$ of respondents would like to change their process of quality management. This could mainly be due to the age of technicians or due to unwillingness to learn new skills. That is why innovation leaders are required to enhance the digitalization of quality management procedures and this way support the improvement principle.

5. The questionnaire proved that the current practice of quality management can be improved by digitalization of related processes, because the following percentages of respondents, who use an application, indicated that:

- all required attachments can be inserted into an application (100\% of respondents);

- required attachments are directly related to the quality inspection (77\% of respondents);

- a report of quality inspection can be generated (77\% of respondents);

- reports are user definable (64\% of respondents);

- statuses of quality inspections can be evaluated (91\% of respondents);

- an application is accessible by other project stakeholders ( $82 \%$ of respondents);

- they consider the use of an application transparent (77\% of respondents);

- they consider the use of an application beneficial (95\% of respondents).

6. Based on the above listed results, the following can be interpreted: 
- Customer focus, engagement of people and relationship management principles can be enhanced by granting permission to other project stakeholders into an application. This way all involved project stakeholders will be able to take an active role in the evaluation of quality inspections.

- Principle of leadership in innovation is inherently fulfilled, because an application is a digital innovation.

- Principle of process approach is fundamentally enhanced, since records of quality inspections are interconnected with the required attachments, can be generated into user definable reports and therefore can be easily submitted to other project stakeholders in printed form, if necessary.

- As far as $95 \%$ of respondents consider use of an application beneficial, it is obvious that the improvement principle is satisfied.

- Evidence-based decision making principle is improved due to the fact that statuses of individual quality inspections are evaluated and stored in a common platform, which can subsequently be used in the future for decision making during the tendering phase.

7. Since the use of a quality management application proved to enhance the principles of ISO 9001, further research into this topic is desirable for the purpose of extensive implementation of quality management application into the construction industry. As well as a research of digital workflows related to quality management within the construction industry.

\section{Acknowledgements}

This work was supported by the Grant Agency of the Czech Technical University in Prague, grant No. SGS19/012/OHK1/1T/11.

\section{References}

[1] Chen L., Luo H. A BIM-based construction quality management model and its applications, Automation in Construction, Volume 46, 2013, pp. 64-73, ISSN: 0926-5805.

[2] Park C.-S., Lee D.-Y., Kwon O.-S., Wang X. A framework for proactive construction defect management using BIM, augmented reality and ontology-based data collection template, Automation in Construction, Volume 33, 2013, pp. 61-71, ISSN: 0926-5805.

[3] ISO9001 Quality management, ISO. [online] [18.03.2019] Available at: http://www.iso.org/cms/render/live/en/sites/isoorg/home/standards/popular-standards/iso9001.html.

[4] International Organization for Standardization, Quality management principles, ISO. [online] [18.03.2019] Available at:

http://www.iso.org/cms/render/live/en/sites/isoorg/contents/data/publication/10/00/PUB100080.ht $\mathrm{ml}$.

[5] Ma Z., Cai S., Mao N., Yang Q., Feng J., Wang P. Construction quality management based on a collaborative system using BIM and indoor positioning, Automation in Construction, Volume 92, 2018, pp. 35-45, ISSN: 0926-5805.

[6] Lee D.-Y., Chi H., Wang J., Wang X., Park C.-S. A linked data system framework for sharing construction defect information using ontologies and BIM environments, Automation in Construction, Volume 68, 2016, pp. 102-113, ISSN: 0926-5805.

[7] Bureau of Labor Statistics, Employed persons by detailed occupation and age, United States Department of Labor, 2018. [online] [18.03.2019] Available at: https://www.bls.gov/ cps/cpsaat11b.htm.

[8] U. C. Bureau, A Glance at the Age Structure and Labor Force Participation of Rural America, The United States Census Bureau. [online] [18.03.2019] Available at: https://www.census.gov/ newsroom/blogs/random-samplings/2016/12/a_glance_at_the_age.html. 